\title{
Anti-CD40 Monoclonal Antibody
}

National Cancer Institute

\section{Source}

National Cancer Institute. Anti-CD40 Monoclonal Antibody. NCI Thesaurus. Code C133877.

Any monoclonal antibody directed ag ainst the antigen cluster of differentiation 40 (CD40). 